\title{
Double Standards and Speech Deficits: What is Sayable for British Muslims After Paris?
}

\author{
by Fatima Khan and Gabe Mythen \\ University of Liverpool; University of Liverpool
}

Sociological Research Online, 20 (3), 2

$<$ http://www.socresonline.org.uk/20/3/2.html>

DOI: $10.5153 /$ sro.3759

Received: 2 Mar 2015 | Accepted: 2 Jul 2015 | Published: 31 Aug 2015

Keywords: British Muslims, Freedom of Expression, Free Speech, Securitization

1.1 The recent terrorist attacks in Paris and Copenhagen have re-ignited debates about freedom of speech across Europe. The Paris attacks took place on $7^{\text {th }}$ January 2015 when two brothers, Saïd and Chérif Kouachi, broke into the offices of the French satirical weekly newspaper Charlie Hebdo armed with assault rifles. They killed 11 people who worked for the newspaper and injured 11 others in the building, going on to shoot dead a French National Police officer outside the building. The two brothers identified themselves as belonging to Al Qaeda in the Yemen. Further related attacks were undertaken by an associate of the brothers, Amedy Coulibaly, who first killed a municipal police officer and then took the lives of four hostages in a Jewish supermarket. A video was subsequently posted online in which Coulibaly pledged his allegiance to ISIS. The Copenhagen attacks took place on February 15th and were conducted by Omar Abdel Hamid El-Hussein who had attempted to enter an event on 'Art, Blasphemy and Freedom of Expression' carrying firearms. It is thought that his primary intention was to assassinate Lars Vilks, the cartoonist responsible for the pictures of the Prophet Mohammed reproduced in the Danish newspaper Jyllands-Posten in 2005. El-Hussein was intercepted as he tried to enter the building by the film director Finn Nørgaard who he shot dead. He fled, later killing a security guard standing outside a Jewish synagogue in the city.

1.2 In the context of the incidents above, the cartoon depictions of the Prophet Mohammed - reproduced in the French satirical magazine Charlie Hebdo and previously in the Danish newspaper Jyllands-Posten - have acted as a flashpoint for violence and a touchstone for debate. In this paper we wish to contribute to this debate, focussing on the issue of the limits of freedom of speech for British Muslims. Through three qualitative studies conducted in the North-West of England over the last decade (see Mythen, Walklate and Khan 2009; Mythen, Walklate and Khan 2013; Khan 2015), we have been able to gather valuable insights into the outlooks of young British Pakistani Muslims, listening to their frustrations, aspirations and fears. Applying the grounded theory method and deploying focus groups and semi-structured interviews, we have accumulated data that enables us to reflect on important issues that affect the lives of young Muslims. While, these studies have primarily been focussed on issues cognate to contemporary debates about freedom of expression[1], here we wish to draw across the studies in order to highlight two key problems which have been frequently raised by participants and which are highly pertinent to public debates post the Charlie Hebdo attacks: standards around freedom of expression and speech deficits. As an ensemble, our studies indicate that these two issues have caused frustration and resentment, whilst also exacerbating feelings of marginalisation. Allying these issues to the current climate of anxiety regarding terrorism post Paris, we posit that the stretchiness associated with freedom of speech - both legally and at the level of political and media discourse - presents serious problems for Muslims in particular and impacts their capacity to voice firmly held opinions. been polarised and polarising, reproducing simplistic binaries. There has, in some circles, been the implicit 
assumption that all Muslims are somehow responsible for the attacks, the talk of 'no-go' and 'Muslim only' areas in European cities and febrile discussion about the caliphistic designs of Islam. Within this discursive vortex, demands have been placed on Muslims to both apologise for and publically condemn the attacks and the ideal of freedom of speech has been twisted in multiple directions. The right to freedom of expression - enshrined in Article 10 of the Human Rights Act - is a cornerstone of liberal democracy. It is designed to uphold unfettered political debate and affords citizens the right to articulate viewpoints without State interference. Article 10 protects the right to express oneself in any medium - including the political and artistic - and protects both popular and unpopular expression, including that which might be shocking. There have been numerous instances in which individuals and institutions have sought to test the limits of Article 10, including the cartoons of the Prophet Mohammed reproduced in Charlie Hebdo. As the popular take up of the 'Je suis Charlie' campaign in France and elsewhere shows, freedom of expression is a highly cherished principle in the West. Up to four million people are thought to have marched to protest against the attacks in France and those that gathered in Paris were joined by political leaders from more than 40 nations. Of course, it cannot be assumed that those aligning with the 'Je suis Charlie' campaign were fervent supporters of the satirical newspaper, or, indeed, necessarily well disposed to the cultural representations that it imparts. It is important to note that there were sizeable pressures on French citizens to protest against the attacks and support the 'Je suis Charlie' campaign as a form of national duty. As Fassin (2015) observes, those that refused to adhere to the mandatory minute of silence in commemoration or who dared to voice an alternative viewpoint were roundly castigated. Nevertheless, the 'Je suis Charlie' campaign coalesced a multitude of values and served as an articulation point for a range of principles around not just free speech but also security, nation, identity and resilience. Nevertheless, there have been currents of opposition against the underpinning sentiments, particularly amongst human rights campaigners concerned about the responsibilities that should accompany free speech (see Hayes 2015). Considerable opposition to the Je suis Charlie' motto surfaced in some Muslim communities, as encapsulated in a Tweet attributed to Dyab Abou Jahjah which raises a range of barbed issues.

1.4 Whilst there was some take up of the 'Je suis Ahmed' slogan in France and elsewhere, this was much less pronounced than the Charlie movement. Nevertheless, the sentiments expressed by Dyab Abou Jahjah and others provide an interesting counterpoint that brings to the surface the complexities surrounding freedom of speech as well as questions of culture, ethnicity and belonging.

\section{Freedom of Speech: Gaps, Traps and Caveats}

2.1 In this section we wish to connect current debates about freedom of speech to issues of cultural representation and expression which have been widely articulated during our studies with young British Muslims. We do not intend to present this data systematically, nor would we claim that the perceptions and outlooks expressed here are in any way representative. It is our aim to utilise the quotes as points of entry into discussion about some of the issues around freedom of speech that affect Muslims in Britain.[2] In particular, we wish to focus on two salient and commonly surfacing issues around the operation of double standards and the existence of speech deficits. We will be arguing that these two problems are key sources of frustration and disenchantment and serve to intensify feelings of social, cultural and political exclusion. We have frequently come across concern about the application of what are perceived to be different sets of principles governing the free speech of Muslims to those of non Muslims. While article 10 indicates that freedom of speech is a universal principle, we have frequently listened to the view that the freedom of speech of Muslims is contingent not absolute. The comments of participants below typify the feeling that it is not acceptable for Muslims to speak about certain 'out of bounds' topics. At the same time, those that choose to denigrate Muslims and Islam are seen to be able to do so without restriction. 
Shah-Jahan:

'So basically everyone else is free to slate Muslims. They're allowed to attack Muslims indiscriminately, take Muslim oil and land. Then on top of all that they're allowed to insult the Prophet. But we can't say anything no matter how bad things are. The hypocrisy of it all makes my head spin'.

In Shah-Jahan's reflections we see the identification of a double standard at play around what is (un)sayable. The question that thus arises is what are the acceptable limits of free speech and who defines this? Notwithstanding Shah-Jahan's observations regarding neo-imperialist sorties, alongside Article 10, there are legal forms of regulation in Britain that are designed to prevent incitement. The Public Order Act (1986) outlaws 'using threatening, abusive or insulting words or behaviour with the intention of stirring up racial hatred' and the Racial and Religious Hatred Act (2006) further prohibits hatred against the person on religious grounds. Yet it would appear that these kinds of legal safeguards do not appear to be offering the protection that many Muslims feel they should be entitled to, as the observations of Amina and Samina infer:

Amina:

'Everyone talks about freedom of speech like it's a real thing that is the same for everyone. You know that even if you don't agree they are allowed to say it'.

\section{Samina:}

'It's just generally OK to hate Muslims. I wouldn't mind if speech really was free for everyone.'

2.3 In previous studies, we have found that the cartoons of the Prophet Mohammed published in the Danish newspaper Jyllands-Posten in 2005 were a source of controversy and anger. This case has frequently arisen unprompted and is seen as symptomatic of the disregard shown for Muslims in some quarters.

\footnotetext{
Khadija:

'It's just easy racism ... how is it pushing boundaries and making people question stuff when you draw a picture of our Prophet as a terrorist? Once you say our Prophet is a suicide bomber, you are saying we all are. It's just another way to torment Muslims. We are the one's being terrorised'.
}

Saif:

'What gets me about these cartoons and stuff is that they say that its pushing boundaries really they are just picking on Muslims who have got it really hard anyway. So, it's not new and exciting, it's just the same old crap that everyone else is saying about Muslims, bullying people who are being attacked anyway'.

2.4 Whilst some commentators have argued that the depiction of the Prophet as a terrorist is religious satire rather than an act of racism (see Hansen 2006), others, such as Modood (2006), reject this assertion. Modood (2006: 7) posits that the Lars Vilks cartoons were the very epitome of racialisation given that they essentialized an entire group by one common characteristic, negatively depicting them as dangerous and inferior. As Modood (2006: 6) reasons, the cartoons are not only about or directed at a single individual, they are designed to ridicule and provoke Muslims per se. This echoes the reference to the ummah in Khadija's assertion and explains why the publication of the cartoons escalated feelings of hostility and victimisation. Nusaiba goes on to speak about how the Jyllands-Posten cartoons form part of a wider context of oppression and coercion experienced by Muslims.

\section{Nusaiba:}

'Those cartoons that say we are all suicide bombers are just another thing that has happened since $9 / 11$. What about stop and search? Yeah, if you take it with Palestine and Iraq and all the dead Muslim kids ... then really you see the bigger picture'.

\section{Moderator:}

'What do you mean by the bigger picture?'

Nusaiba:

'I mean the cartoons are just the tip of the iceberg. I think its just another thing that we are expected to just accept. It's as if they want to make it as hard as possible for Muslims in this country or Europe. So it's OK for us to be searched because we are Muslim, killed because we are Muslim not get jobs because we are Muslim, get abused on the street and slagged off in the papers. On top of all that we have to watch whilst they say those things about our 
Prophet. They want to insult us in the worst possible way and for us to say "yeah, we are loving this". Well it's just too much'.

As Nusaiba suggests, what needs to be fully understood and appreciated is the place of representations that purport to be satirical within the wider tapestry of anti-Muslim discourses and wider forms of inequity and exclusion. As Modood (2006: 5) points out, the Jyllands-Posten cartoons were a flashpoint, but one located within a particular set of processes and conditions affecting and shaping the identities and values of Muslims, including, inter alia, 'inferior protective legislation, socio-economic marginalisation, cultural disdain, draconian security surveillance, the occupation of Palestine and the international 'war on terror'. Almost ten years on from these comments, their resonance has not diminished. The assent of the political far right in Greece, the birth of the anti-Islamic PEGIDA movement in Germany, rising levels of racially motivated attacks on Muslims, the civilian deaths resulting from US drone strikes in tribal areas in Pakistan and Afghanistan and a climate in which Islamophobia has, in the words of Baroness Sayeeda Warsi, 'passed the dinner table test' have intensified feelings of marginalisation and oppression felt by Muslims domestically and globally (see Anthony 2011).

While we have detected strong currents of uncertainty and cultural prohibition around the borders of free expression amongst the young British Muslims in our studies, these have been further compounded by a sense of uncertainty about what might constitute a legal infringement. Prosecutions of Muslims under counter-terrorism legislation introduced over the last decade have created a climate of unease in which the boundaries regarding what is sayable in opposition are unclear. In particular, we have listened to concerns about the charge of encouragement of terrorism, introduced in the Terrorism Act (2006).[3] This offence was designed to criminalise individuals that 'praise or celebrate' terrorism in ways which may encourage others to emulate such violence. The clause in the Act which has proven most controversial is that of 'glorification' which covers statements likely to be understood as indirectly encouraging acts of terrorism. Notwithstanding legal arguments about whether or not offences such as glorification of terrorism are compatible with freedom of political speech, we have frequently encountered the view that freedom of speech for Muslims in Britain has been curtailed. Both Shah Jahan and Basanti elaborate on this point, indicating feelings of frustration and powerlessness.

\begin{abstract}
Shah Jahan:
'What I can't get my head around is they have made it a crime. They've actually brought in laws to force Muslims into silence, to not have any opinions. They expect us to suffer in complete silence, but then let anyone who wants to say what they want about us. Anyone can offend us, anyone. So the Government makes it illegal for us to express our opinions, while the same time spouting how freedom of speech is sacred. Then on top of that, where are all the people protesting for our freedom of speech? Every Tom, Dick and Harry's got something to say about the Danish cartoons, how it's their right ... what about our rights?'
\end{abstract}

\begin{abstract}
Basanti:
'They've made it so we can't say anything without it been seen negatively. It's like if you say you support Palestine, you're seen as been some sort of extremist, supporting terrorism or something. I'm pretty sure you can't support anything that's linked to any sort of cause supported by terrorists anymore. So like with that, you can't even say anything, even though every day they are killing more and more Palestinians; destroying their lives. But then you get every other idiot slagging us off whenever they want ... BNP calling us cockroaches, those cartoons - showing our Prophet as a terrorist for God's sake - but no, that's okay because that's freedom of speech'.
\end{abstract}

2.7 These comments are illustrative of a perceived double-bind regarding free speech for Muslims. The points raised by Shah-Jahan and Basanti also illumine the contradiction between righteous defence of the principle of freedom of speech in some instances and its apparent withdrawal in others. Alongside the implicit criticism of the 2006 Terrorism Act, Shah-Jahan believes that freedom of speech only receives societal endorsement if it conforms with dominant discourses. Meanwhile, Basanti draws attention to the elephants in the room such as the situation in Palestine which Muslims care deeply about but feel unable to publically discuss.

\title{
The Legitimation of Islamophobia?
}

3.1 In many respects, the debate regarding the protection of free speech in the Charlie Hebdo case runs parallel with that previously rehearsed in the Jyllands-Posten episode. As Modood (2006: 7) noted at that juncture, an atypical intersection occurred between far-right leaning individuals and the 'liberal intelligentsia'. Notwithstanding the mixed politics and contorted rationales involved, what has frequently been missing in such debates has been the issue of responsibility. Having the right to be provocative does not mean that it should be exercised either with impunity or recklessly. While article 10 is a qualified right that can be overridden in instances in which interests of national security are threatened or the protection of the reputation or rights of others is at stake, the thorny question remains: which instances are such qualifications made, by whom and 
why? While this remains a somewhat murky area, what is clear to us is that many young Muslims such as Rehan feel unfairly persecuted by racist individuals, targeted by right wing political groups and rendered vulnerable by the uneven application of law.

\begin{abstract}
Rehan:
'It's a strange position for Muslims I think. So, racism against Muslims, whatever you call it, from the people you expect it from like all those far-right groups, like the BNP, EDL and all those bigots you get, they get to say all the crap you expect them to say. Nothing happens to them. How's that right? It's like with those cartoons, they were racist, simple as. Do you know what, that's okay because that's what you expect? For me what makes it really bad is that all those freedom loving politicians and the papers, they support these racists ... They say its freedom of speech. It's like it's a badge of honour to slag off Muslims and then say 'well I can, because it's my right to'. There's no support for Muslims, not from any direction ... even people who're are quite liberal, easy going, even they won't do anything. I think the problem is they don't really tolerate religion. That's what's at the bottom of it. So they make a point of not supporting it in anyway. Basically we're attacked from all sides'.
\end{abstract}

3.2 This feeling of 'being attacked from all sides' is deeply troubling and augers ill. In Rehan's view, Muslims are subject to verbal attacks from right-leaning publications that use freedom of speech as a mechanism to legitimate the denigration of Islam. In this manner the charge of Islamophobia is by-passed and liberal minded individuals who support freedom of speech to the hilt are, in effect, serving to sanction Islamophobic abuse. Salim offers a similar perspective on the Jyllands-Posten cartoons, connecting this incident to the controversy over Salman Rushdie's Satanic Verses[4].

\begin{abstract}
Salim:
'Yeah, it's just a fancy cover story for bullying Muslims and picking the same scab over and over again, the one that they have proof that is the worst thing for us ... It's just a way of being able to insult Muslims in the worst possible way, and get everyone to support you for doing it. They know exactly what they are doing. They know from what Rushdie did, if you insult the Prophet it'll really hurt them. They know they can say what they want about Muslims and use a get out of jail free card'.
\end{abstract}

3.3 The continued significance of the Salman Rushdie affair is highlighted by Salim, alongside an assertion that the cartoons of the Prophet Mohammed were designed to cause anger and hurt throughout the ummah.

3.4 In this thought-piece we have sought to draw attention to contests over the issue of free speech. Giving voice to the opinions of some of the young British Muslims who have participated in our studies, we have highlighted the deleterious long-term consequences of flirtations with article 10. Our discussion has highlighted perceived double standards and speech gaps around topics of geopolitical concern. We would suggest that what appear formally as universal rights feel very much sectoral for those located at the sharp end. While we have presented evidence from small-scale studies that is not generalizable, data from larger scale surveys does not run counter to our conclusions. For example, a recent ComRes (2015) survey involving a thousand British Muslims indicated that $46 \%$ felt that being a Muslim in Britain is difficult due to prejudice against Islam. The further tightening of security discourses signalled by recent extensions to PREVENT and new restrictions introduced in the 2015 Crime and Security Act ${ }^{[5]}$ are particularly troubling for Muslims and add a further mechanism for the policing of oppositional viewpoints (McGarry and Mythen 2015). When extremism is defined as broadly as 'vocal or active opposition to British values, including democracy, the rule of law, including liberty and mutual respect and tolerance of different faiths and beliefs' (Prevent Duty Guidance 2014) there is a tangible danger that political critique and legitimate dissent are transmuted into illegal practices.

\title{
Notes
}

The study which reported in 2009 was primarily focused on Islamophobia and victimisation, that which reported in 2013 toward identity politics and the 2015 study was oriented toward the impacts of counter-terrorism regulation British Muslims post 9/11.

The names of participants in each of the studies have been changed to protect anonymity. The studies involved young Pakistani British Muslims, aged between 18 and 26, living in the North-West of England. In each study 32 participants were involved, divided equally by sex. Participants were accessed through known contacts within the Muslim community and snowball sampling. 
encourage, incite or glorify terrorist acts, including more generalised statements of incitement.

The Satanic Verses controversy or Rushdie Affair describes the reaction to the publication of Salman Rushdie's Satanic Verses in 1988. Many Muslims were outraged and protested against the publication of the book, arguing that it was denigrating to both Islam and the Prophet Mohammed (1988). The Ayatollah of Iran issued a fatwa against Rushdie and, with his life having been threatened, he was forced to go into hiding.

For full details about the range of powers proscribed in the Act see:

http://www.legislation.gov.uk/ukpga/2015/6/contents.

\section{References}

ANTHONY, A. (2011) 'Sayeeda Warsi: A matter of pride and prejudice', The Observer, January 23.

COMRES (2015) BBC Radio 4 Muslim Poll. London: ComRes.

FASSIN, D. (2015) 'A French Requiem', Dissent, February 7. Viewable at http://www.dissentmagazine.org/blog/french-requiem-after-charlie-hebdo. Accessed June 152015.

HANSEN, R. (2006) 'The Danish Cartoon Controversy: A Defence of Liberal Freedom', International Migration, 44 (5): p. 42-51.

HAYES, B. (2015) 'No, we're not all Charlie Hebdo, nor should we be'Open Democracy, January 9.

KHAN, F. (2015) 'Negotiating British Muslim Identities: Hybridity, Exclusion and Resistance', Unpublished PhD Thesis, University of Liverpool.

MCGARRY, R. and MYTHEN, G. (2015), 'Beware the security creep into British universities',The Conversation, March 2.

MODOOD, T, (2006) 'The Liberal Dilemma: Integration or Vilification?' International Migration, 44(5): p. 4-7.

MYTHEN, G., WALKLATE, S. AND KHAN, F. (2009) 'I'm a Muslim, but I'm not a Terrorist': Risk, Victimization and the Negotiation of Risky Identities' British Journal of Criminology, 49 (6): p. 736-754.

MYTHEN, G., WALKLATE, S. AND KHAN, F. (2013)'Why Should We Have to Prove we're Alright?' CounterTerrorism, Risk and Partial Securities', Sociology, 47(2): p. 382-397.

PREVENT DUTY GUIDANCE: A CONSULTATION (2014) London: HMSO. 